\title{
Analysis of the Statement of Stockholders' Equity in the Context of an Institutional Platform for Small Business Sector of the Republic of Moldova
}

\author{
Irina Golochalova \\ Department of Accounting and Economic Informatics, Moldova State University, Chisinau, Republic of Moldova
}

Email address:

monomah5@yandex.ru

\section{To cite this article:}

Irina Golochalova. Analysis of the Statement of Stockholders' Equity in the Context of an Institutional Platform for Small Business Sector of the Republic of Moldova. Journal of Finance and Accounting. Vol. 7, No. 5, 2019, pp. 136-145. doi: 10.11648/j.jfa.20190705.12

Received: August 11, 2019; Accepted: September 5, 2019; Published: September 19, 2019

\begin{abstract}
Small business sector dominates in the Moldavian economy. In order to support and further develop this sector in Republic of Moldova the institutional platform was formed and implemented. The efficiency of that institutional platform, however, must be judged by the context of financial result, which is accounted by means of a financial statement. According to modern accounting methodology - methodology of International Financial Reporting Standards (IFRS) the purpose of financial reporting is the presentation of useful information to a wide range of users to make managerial decisions. The users primarily consist of owners (shareholders and investors) who are interested in information about social capital changing. The study aims at establishing the correspondence between conceptual space of accounting and financial reporting system for Small and Medium-Sized Enterprises (SMEs) in the Republic of Moldova and requirements of the modern accounting methodology in the in the context of transition to an innovative development path. In the paper we paid attention to the review of the Statement of Stockholders' Equity, which was carried out in the following stages: General characteristics of its structure in the system of Financial Statement of the Republic of Moldova; Analysis of the conceptual basis and evolution of its model; Disclosure of its peculiarities as a form reporting the financial statement system in the Republic of Moldova.
\end{abstract}

Keywords: Small and Medium-sized Enterprises, Law of Accounting of Moldova, Modern Accounting Methodology, The Economic and Legal Approaches, Financial Statement, Statement of Stockholders, Equity

\section{Introduction}

It is known that from the end of the XXth century, the world economic trends were influenced by organizations related to the small business sector. These organizationsSMEs, having in fact limited own potential and, consequently, being in worse economic conditions, though, contributed to a significant increase in the gross domestic product, and sometimes created "success stories" of economic development of an individual state. The SMEs sector constitutes a vital part of economics in both developed and developed countries. However, their role in developed nations is far more meaningful than in developing economics [1].

Small and medium-sized enterprises are an important force to facilitate of country's economic development, but the survival and development situation of small and medium- sized enterprises in the country is getting worse and the acute financing constraint is one of the key resistance to the development of small business sector [2]. For eliminating the emerging problems and creating the most favorable conditions for the functioning of the small business (SB) sector, an effective institutional platform is needed. This should clearly be enshrined in the strategic acts of the individual state.

An institutional platform is aimed at creating equal competitive conditions for SB sector in the business environment and for this purpose the following elements are included: the legislative and regulatory framework; professional training and development of entrepreneurial skills; mechanisms and instruments of financing. Within the framework of institutional platform, priority areas are singled out. Today, in the context of the transition from a consumption model to an innovative economy model, based 
on knowledge, such as area in the Republic of Moldova (RM) indicates the development of innovative activities in the SB sector, which is clearly enshrined in the strategic acts of the country. Consequently, one of the main objectives of the accounting and reporting reform is to improve the legislation on small business accounting and to develop national accounting standards for small business [3].

The institutional platform, both at the international level and in Moldova, in the context of fulfilling its obligations of association with the European Union, is clearly structured, but its effectiveness is manifested in the financial position and financial results of SMEs that are recognized in the financial statement.

According to modern accounting methodology, the purpose of financial reporting is the presentation of useful information to a wide range of users, first and foremost, to owners (shareholders and investors) who are interested in information about changing the social capital (the received profit and its distribution) [4]. Investors and other users of financial statements always need the legal protection of their interests in getting fair financial information [5]. In order to fulfil the purpose for making managerial decisions, compiler organizations should provide not only information on economic resources, but also the reasons that led to their changes. However, in order to make such decisions such as increasing the efficiency of using equity capital, attracting new investors, forecasting the growth of the organization's capital as a whole, which is important, for both owners and the management of the organization, the information field of the balance sheet and the profit and loss statement are not enough. Moreover, in the transition to an innovative model of economic development, such a format of information limits the ability to make decisions for organizations belonging to the SMEs.

Therefore, in order to eliminate this shortcoming, in terms reliable of information on equity capital and its changes in the composition of financial statements, the form "Statement of Stockholders' Equity" is provided, which is intended to be a decoding to the corresponding section of the balance sheet.

The system of financial statement of separate jurisdiction, its components, forms of financial statement and their content depends on several factors: accepted accounting model, the level of economic development, and the ratio of small and large businesses in business environment. In the context of the above following questions arise:

1. Is there a conceptual area in terms of determining the structure of financial reporting and generating reliable information on the results of the small business organizations sector activity in the context of transition to an innovative development path in the financial reporting system of the Republic of Moldova?

2. Does the Statement on changes in equity capital as form of financial statement of the Republic of Moldova meet the interests of information users on the state of equity capital entities, including SMEs, and requirements of modern accounting methodology?

The scientific works in the field in the RM are devoted to the problems of development of the SB sector: by developing of the concept of financing and simplification of access to it [6], under the aspect of introducing forms and methods of supporting entrepreneurship [7], from the point of view of the application of motivational management [8]. It should be noted that various issues are also discussed in the economic scientific literature, theoretical views are set out, and accounting methods are suggested, but the problem of improvement of the financial reporting of the SB sector in the context of an innovative vector of economy remains open, fact which confirms the relevance of the studied topic.

\section{Methodological of Research}

\subsection{General Characteristics of the SME Sector Condition}

The aim of this paper is to evaluate the institutional platform for the development of the SB sector of the Republic of Moldova (RM) and to suggest a hypothesis, which will be carried out in two stages.

An already indisputable fact is that; the small business sector has a significant impact on the main indicators that characterize the level of economic development of a single region. The RM is not an exception. This influence is not only significant, it has a multidimensional character, since it affects both economic and social, and sometimes political processes occurring in the country. That is why it is important to establish those indicators on the basis of which it is possible to assess both the economic and social contribution of the SB sector to the national economy.

For large business organizations, the traditional indicators on the basis of which their social and economic impacts on the economy are established are the size of social capital and its growth. For the SB sector organizations, the use of these indicators is economically inexpedient, and sometimes it is not possible, so it became necessary to identify those that allow assessing the socio-economic contribution of the SB sector. Such indicators were established, moreover, they were taken as a basis, as criteria for qualification and referring organizations to the SB sector.

According to the author, the establishment of indicators of economic (annual sales revenue, total annual book value of assets) and social character (annual average number of employees), indicates a new concept of the SB sector, the essence of which in shifting the emphasis from positioning SB as units in need of government support on the understanding of the SB sector as an economic unit of the region.

One evidence to the fact these indicators are universal and economically feasible of using is the research conducted by scientists Kot, Goldbach and Ślusarczyk (2018). In their study, which related to the use of supply of chain management for financial development of SMEs, the basis of the methodological approach introduced one of this classification indicator - employment size [9].

Further, we will disclose the current state of the SB sector in Moldova. According to the published National Bureau of Statistics (NBS) data as of 31.12.2018, the structure of the 
small business sector in the RM represented by three categories: medium, small and micro enterprises.

In total, 51.6 thousand enterprises belonging to the $\mathrm{SB}$ sector in Moldova account for $98.7 \%$ of the total number of economic units operating in the country. The number of employees employed in this sector in 2017 is 313.5 thousand people, which in percentage terms is $61.2 \%$ of the employed population, the contribution to the state budget as revenue from sales is determined in the amount of 6330.01 thousand euro or $41.5 \%$ of sales income total for the economy. This information presented in table 1 in the context of individual directions (table 1).

Table 1. Quantitative indicators of the SMEs of the RM for 2017 (by areas of activity).

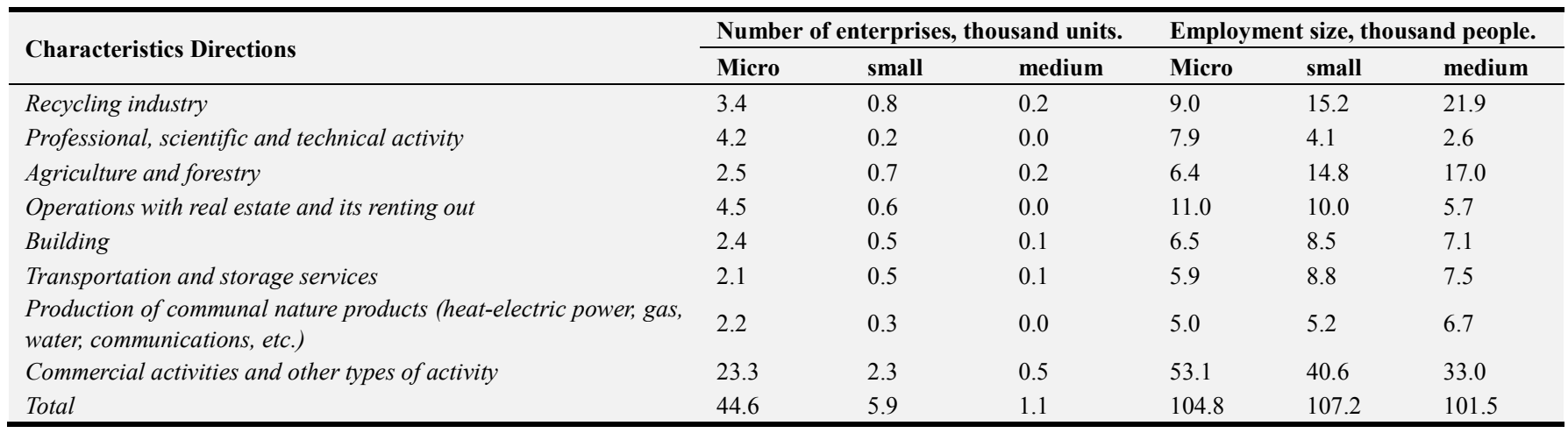

Data sources: developed by the author on the basis of [10].

The analysis of the situation shows that: commercial activities occupied the leading position; even if they are divided according to the types of activity, micro-enterprises retain the dominant position by number, while the largest numbers of employees are employed in small enterprises. In the view of research economist Aculay (2015) this ratio is unpromising for the SB sector since the main contribution to the national economy and to the employment of the population is made by small and medium-sized enterprises [11]. In terms of the characteristics of the economic impact of the SB sector on the state budget, we present an estimate of the cost criteria of the SB sector, both by the areas of activity (table 2).

Table 2. The cost indicators of the SMEs of the RM for 2017 (by directions of activity).

\begin{tabular}{|c|c|c|c|c|c|c|}
\hline \multirow[t]{2}{*}{ Characteristics Directions } & \multicolumn{3}{|c|}{$\begin{array}{l}\text { Incomes from sales of enterprises, } \\
\text { thousand euro. }\end{array}$} & \multicolumn{3}{|c|}{$\begin{array}{l}\text { Profit (loss) before taxation of } \\
\text { enterprises, thousand euro. }\end{array}$} \\
\hline & micro & small & medium & micro & small & medium \\
\hline Recycling industry & 99.13 & 259.33 & 340.16 & $(1.07)$ & 9.77 & 24.64 \\
\hline Professional, scientific and technical activities & 90.98 & 68.04 & 30.92 & 21.70 & 11.84 & 0.45 \\
\hline Agriculture and forestry & 105.98 & 236.02 & 183.17 & 11.93 & 24.26 & 15.32 \\
\hline Operations with real estate and its renting out & 87.90 & 114.20 & 81.87 & 15.78 & 9.18 & 7.00 \\
\hline Building & 99.14 & 180.65 & 159.67 & 3.32 & 12.12 & 12.02 \\
\hline Transportation and storage services & 111.58 & 233.09 & 128.36 & 2.48 & 12.68 & 2.16 \\
\hline $\begin{array}{l}\text { Production of communal nature products (heat-electric power, gas, } \\
\text { water, communications, etc.) }\end{array}$ & 52.28 & 70.80 & 94.11 & 5.78 & $(2.66)$ & 3.13 \\
\hline Commercial activities and other types of activity & 1053.83 & 1374.80 & 1074.12 & 18.48 & 35.75 & 41.73 \\
\hline Total & 1700.68 & 2536.95 & 2092.39 & 78.39 & 112.96 & 106.45 \\
\hline
\end{tabular}

Data sources: developed by the author on the basis of [10].

The presented data show that the category of small enterprises is the most profitable (112.96 thousand euro) and the largest contributor to the state budget (2 536.95 thousand euro), while the economic impact of other categories is significantly lower. A similar study made Kot, Goldbach, Ślusarczyk (2018) and their results converged with some of our conclusions. In the process of research they found that SMEs dominate in the Romanian economy and made the conclusion that development of the Romanian economy is based on the development of the Romanian SMEs [9].

Summarizing the information provided, the author concludes that the social contribution of the SB sector to the national economy is the most significant - employment in this sector makes up $61.2 \%$ of the total number of employees, a significantly modest economic contribution - sales revenues from products and services produced - only $41.5 \%$ at $98.7 \%$ of the total number of enterprises. Moreover, the imbalance between quantity, due to a significant share of microenterprises in this sector, and the economic result proves the existence of a number of problems that can be solved by implementing effective public policies, the concept of which will be considered below.

We consider it appropriate to note as the focus of the research is on studying the institutional platform of the SB sector and its impact on the content of financial statements of organizations related to this sector, the author does not consider the change in quantitative and cost parameters in dynamics. 


\subsection{Legislative Framework of RM as Element of Institutional Platform SMEs: Evaluation of Implementation}

The new vision of the SMEs in the RM, required an appropriate institutional platform, the basic component of which are strategic acts and documents in which is consolidated the idea and main directions of public policy the concept of maintaining and developing SB.

It is known that for the first time the concept of support and development of the SB sector at the European level was fixed in the "Small Business Act" (hereinafter referred to as SBA), which clearly defines the key role of this sector in economic growth, and is defined a number of its principles, among which: the creation of an institutional environment; facilitating access to finance; development of a favorable business environment [12].

Since Republic of Moldova in 2014 became an associate member of the $\mathrm{EU}$ on the basis of an association agreement ratified by the Parliament of the RM and parliaments of 28 EU member states and the European Parliament, the Government of the RM assumed a number of obligations, including the reform of the legislation of the SB sector, which is based on the concept of state support. We shall open its basic provisions. With an according to realizing the obligations of the association in 2012, the Government adopted the Strategy of the RM for supporting small and medium-sized enterprises for 2012-2020 (hereinafter referred to as the Strategy). This Strategy provide a policy framework for the development of SMEs of the RM in the context of transition from a model of economic development based on consumption to a new paradigm focused on innovations, to European integration and world economic trends [13]. The conceptual thesis of the Strategy is: SMEs of the RM is a factor of sustainable economic growth and national competitiveness.

However, the effectiveness of reforms is manifested not so much in the formation of the concept of development and the adoption of strategic documents, but in the effectiveness of their adaptation in practice and the results obtained. To establish this fact, it is necessary to carry out an assessment of the implementation of state policy using a certain methodology. The Moldovan researcher Aculay (2015) notes that in the world practice several methods for assessing the policy of maintaining the SB sector on the basis of reliable indicators are known and he gives a brief description of them [11]. One of these methods, using special indicators and based on a 5-point system, is the assessment (control) that European experts periodically conduct on the conformity of state policy and implemented measures to the principles of SBA by the countries of the Eastern Partner (EaP) region.

In the report, SME Policy Index: Eastern Partner Countries 2016 - Assessing the Implementation of the Small Business Act for Europe" (hereinafter referred to as the Report), coordinated by the European Commission, clearly demonstrates the results of applying this methodology - an assessment of compliance with all 10 principles of effective support of small business is given [14]. In general, the Report indicates that according to the results of the 2012 assessment (the date of the first assessment - the course of the implementation of the SBA), many recommendations were implemented by the countries of the EaP format, and a significant, albeit uneven, progress towards success was identified. Since the Strategy highlights such area of the state policy of SB support as improving legislation, we will dwell in more detail on evaluating the indicators of the Republic of Moldova in the above-mentioned area based on the Report.

So, with regard to the assessment of direction (area) 3 "Regulatory and Legal framework of the Economy" it was noted that compliance with the basic principle of the SBA requires the public sector to take into account the interests of the $\mathrm{SB}$, starting with ensuring the legislative and regulatory framework, which should guarantee assistance in the development of this sector.

Taking into account the content component of this stage, the evaluation model is formed on the basis of three components, which allow to assess the completeness of the institutional base; the effectiveness of mechanisms to simplify legislation and their regulatory impact, the degree of development of the dialogue between the public and private sectors. The values of the estimates for the correspondence of direction 3 to the SBA principle are presented in table 3 .

Table 3. Evaluation of the RM criteria for the correspondence of direction 3 to the SBA principle.

\begin{tabular}{llll}
\hline Sub-direction Criteria & "Institutional base" & $\begin{array}{l}\text { "Simplification of legislation and } \\
\text { assessment of regulatory impact" }\end{array}$ & $\begin{array}{l}\text { "Consultations between the public } \\
\text { and private sectors" }\end{array}$ \\
\hline Planning and development & 4.67 & 2.60 & 3.87 \\
Introduction & 3.89 & 3.87 & 2.80 \\
Control and assessment & 4.19 & 1.44 & 2.33 \\
Weighted mean & 4.22 & 2.94 & 3.13 \\
\hline
\end{tabular}

Data sources: developed by the author on the basis of [14].

Despite the fact that a number of activities have not yet been implemented, the general conclusion of the Report on the results of this direction: Moldova is recognized as the leader of improvement of the legal framework in the countries of the EaP format (the institutional development platform for the SMEs has been improved; the legislative and regulatory framework of the accounting system for this sector, of taxation and administration affecting SB activities has been improved and other) [14].

The scientist Levitscaia (2017) in the work studied and disclosed the issue of institutional platform evaluation and the effect of its introduction into entrepreneurship in the 
Republic of Moldova was from the scientific point of view. The conclusion drawn by Levitscaia (2017) that entrepreneurship is only beginning to develop in the RM and today does not have the necessary legislative and financial base, does not enjoy significant support from the state, which has just begun to solve these problems [15].

We consider it appropriate to point out that following the results of the assessment of compliance with the principles of the SBA, a wide range of measures recommended to adopt of RM, which include improving the institutional platform; modernization of regulatory framework in key areas, including in the accounting system for SB. In this context, it is worth emphasizing that in pursuance of the EU recommendations Law No. 179 of July 21, 2016 of the RM "On Small and Medium-Sized Enterprises" was drafted and enacted, which establishes the legal basis for the SB activity sector and state support measures for their creation and development. A new law has been approved in the accounting system - Law No. 287 of 15.12.2017 "On Accounting and Financial Reporting" (effective from 01.01.2019), in which the requirements of the European directives regarding financial reporting models are transposed depending on the category of subjects of the SB sector.

According to the recommendations of the EU, Law No. 179 of July 21, 2016 of the RM "On small and medium-sized enterprises", with amendments of 16.03.2018, was drafted and entered into force [16], which establishes the legal framework for the activity of the SB sector and measures of state support for their creation and development. With the purpose of creating an enabling basis for the development of SMEs. Criteria for reference to the sector SB are establishes in article 5 of this law, which allow organizations to classify as micro-, small and medium enterprises. In Law No. 287 of 15.12.2017 "On Accounting and Financial Reporting" (hereinafter referred to as the Law No. 287), when classifying economic subjects, the emphasis is shifts from their social significance to the economic contribution in the national economy, as evidenced by the establishment of appropriate evaluation criteria for micro, small and medium enterprises [17]. The indicators that fixed in the RM at the legislative level is present in table 4.

Table 4. Classification evaluation criteria for classifying the organization of the SMEs.

\begin{tabular}{|c|c|c|c|c|c|c|}
\hline \multirow{2}{*}{ Law of the RM Indicators } & \multicolumn{3}{|c|}{ No. 179 of $21.07 .2016[16]$} & \multicolumn{3}{|c|}{ No. 287 of 15.12 .2017 [17] } \\
\hline & micro & small & medium & micro & small & medium \\
\hline annual average number of employees, people & not more than 9 & from 10 to 49 & from 50 to 249 & 10 & 50 & 250 \\
\hline annual amount of revenues from sales, million euro & up to 0.46 & up to 1.26 & up to 2.53 & 0.57 & 6.45 & 32.17 \\
\hline total annual book value of assets, million euro & up to 0.46 & up to 1.26 & from 2.53 & 0.28 & 2.22 & 16.11 \\
\hline
\end{tabular}

Data sources: developed by the author on the basis of $[16,17]$.

Law No. 287, article 4 specifies that for the classification of a particular group, it is sufficient to observe two criteria out of three established [17]. Thus, article 5 of the mentioned act is in accordance with NAS:

a. micro-entities maintain a double-entry book-keeping record and make up the abbreviated financial statements;

b. small entities keep accounting by double entry and make simplified financial statements; c. medium entities keep accounting by double entry and make full financial statements.

In this case, it is possible for an organization belonging to any classification group to maintain records and report in accordance with International Financial Reporting Standards (IFRS) [17].

Conform Law No. 287 the financial statements include the following forms (table 5).

Table 5. The composition of financial statements when applying a full accounting system.

\begin{tabular}{|c|c|c|c|c|c|c|}
\hline Accounting system & Balance Sheet & $\begin{array}{l}\text { Income } \\
\text { Statement }\end{array}$ & $\begin{array}{l}\text { Statement of } \\
\text { Cash Flows }\end{array}$ & $\begin{array}{l}\text { Statement of } \\
\text { Stockholders' Equity }\end{array}$ & $\begin{array}{l}\text { Notes to the Financial } \\
\text { Statement }\end{array}$ & $\begin{array}{l}\text { Management } \\
\text { report }\end{array}$ \\
\hline a full & Yes & Yes & Yes & Yes & Yes & Yes \\
\hline a simplified & Yes & Yes & $\times$ & $x$ & Yes & $x$ \\
\hline an abbreviated & Yes & Yes & $\times$ & $\times$ & Yes & $x$ \\
\hline
\end{tabular}

Data sources: developed by the author on the basis of [17].

At the same time, the Law No. 287 allows the subject of the model to select the report model next after compulsory application of the model. Thus, an entity obliged to draw up reduced or simplified financial statements can choose to compile complete financial reports [17, art. 20].

It is important to highlight that the peculiarity of the national accounting and reporting system of the RM is its directness. In the context the author came forward with the following Hypotheses $(\mathrm{H})$ :

H1: There is no integral conceptual space in terms of determining the structure of financial reporting and generating reliable information on the results of the small business organizations sector activity in the accounting and financial reporting system of the Republic of Moldova in the context of transition to an innovative development path.

H2: The Statement of Stockholders' Equity as form of financial reporting of the Republic of Moldova does not meet the interests of users of information on the state of equity capital entities, including SMEs, and requirements of modern accounting methodology. 


\section{Conceptual Analysis and Research Hypotheses}

According to modern accounting methodology, the purpose of financial reporting is the presentation of useful information to a wide range of users, first and foremost, to owners (shareholders and investors) who are interested in information about changing social capital (profit received and its distribution) [18]. In order to execute this purpose of useful information for the adoption of managerial decisions, compiler organizations should provide not only information on economic resources, but also the reasons that led to their changes.

There are the balance sheet and the profit and loss statement the main forms of reporting, as is known. However, or making such decisions as increasing the efficiency of using equity capital, attracting new investors, forecasting the growth of the organization's capital as a whole, which is important, both for owners and for the management of the organization, the information field of this reports are not enough. Therefore, in order to eliminate this shortcoming, in terms of information on equity capital and its changes the form "Statement of Stockholders" Equity" provided in the composition of financial statements.

Moreover, in the transition to an innovative model of economic development, such format of information limits the ability to make decisions for organizations belonging to the SMEs. Not a secret these organizations are limited in financial resources and need additional financing, and the rationale for obtaining it for the implementation of an investment, and sometimes an innovative project is possible only based on complete information about the current state of the organization's equity capital.

At first we will dwell in more detail on the format of the Statement of Stockholders' Equity (hereinafter referred to as the Statement Changes in Equity Capital - SCEC) adopted in Moldova that a hypothesis $\mathrm{H} 1$ and $\mathrm{H} 2$ is confirmed.

The procedure for the preparation and submission of this report is governed by the NAS "Presentation of Financial
Reports", which is applied by business entities with the exception of public interest entities and those that apply IAS 1 "Presentation of Financial Statements", non-profit organizations and budget organizations [17, art. 5 (11)]. A similar procedure for the selection of the presentation model and the composition of the financial statements is indicated in the NAS "Presentation of Financial Statements" [19, par. $7,8]$.

According to the provisions of the designated standard, the SCEC characterizes the presence and change during the reporting period of equity capital, the constituent elements of which are: social capital and Premiums on capital, reserves, retained earnings (uncovered loss), its other elements [19, par. 97]. Thus, the recommended NAS "Presentation of financial statements" composition of equity capital generally meets the generally accepted requirements. The standard describes each component and discloses the content of operations under the influence, which will change its balance at the end of the reporting period [19, par. 104-121].

In accordance with the NAS "Presentation of Financial Statements", elements of equity are valued in accordance with the NAS "Equity capital and liabilities", the purpose of which, in particular, is to establish the procedure for accounting for equity capital and disclosure of relevant information in the financial report [20, par. 98].

The SCEC established directive the format and based on the formula: for each element of equity capital is indicated the balance at the beginning of the reporting period, the amount of increase and decrease during the period and the balance at the end of the reporting period [19, par. 99]. In addition, the standard requires that equality between the residuals of equity capital elements presented in the SCEC at the beginning and end of the reporting period and balances on the relevant balance sheet items [19, par. 101]. This is a confirmation that this report is an addition to the balance sheet.

The Fragment of SCEC prepared organizations of SB sector of RM presented in table 6 .

Table 6. Fragment of Statement Changes in Equity Capital of RM.

\begin{tabular}{|c|c|c|c|c|}
\hline Indicators & Balance at the beginning & Increase & Decrease & Balance at the end \\
\hline Social capital & 405400 & 300000 & $\mathrm{x}$ & 705400 \\
\hline Premiums on capital & $\mathrm{x}$ & $\mathrm{x}$ & $\mathrm{x}$ & $\mathrm{x}$ \\
\hline Reserves & $\mathrm{x}$ & 140500 & $\mathrm{x}$ & 140500 \\
\hline Profit, includes: & 8344338 & 2804869 & 634445 & 10514762 \\
\hline amendments to the results of previous years & $\mathrm{x}$ & $\mathrm{x}$ & 193945 & $(193945)$ \\
\hline undistributed profit (uncovered loss) of previous years & 8344338 & $\mathrm{x}$ & 300000 & 8044338 \\
\hline used profit of the reporting period & $\mathrm{x}$ & $\mathrm{x}$ & 140500 & $(140500)$ \\
\hline Other elements of equity capital & $\mathrm{x}$ & $\mathrm{x}$ & $\mathrm{x}$ & $\mathrm{x}$ \\
\hline Total equity capital & 8749738 & 3245369 & 634445 & 11360662 \\
\hline
\end{tabular}

Data sources: developed by the author on the basis [19].

The author emphasizes that the two specified requirements are of a technical nature, the main thing when preparing any form of financial reports, including the SCEC, is the correspondence to the qualitative characteristics that the information of financial statements should answer, namely: clarity, relevance, reliability and comparability. Besides, in the process of reforming the accounting system of the RM and its adaptation to international and European regulations, 
the following thesis was accepted: the purpose of financial reporting is to provide useful information to a wide range of users in order to make economically viable decisions with respect to the reporting organization [19]. This requirement is methodological in nature. This is the first argument in context hypothesis $\mathrm{H} 1$.

It may be relevant to mention that a number of amendments made to the existing National Accounting Institution of the RM in the process of improving the legislative framework and reforming the regulatory framework for accounting and reporting, which affect the requirements for reporting information in the SCEC. Some of these amendments are of a terminological nature, while others are of a methodological nature. Thus, the entry into force of the modification of NAS (01.01.2019) new concept of "social capital" used in instead of the term to "authorized (statutory) capital" which is one of the attempts to bring the content of the accounts in line with its socially oriented purpose. Premiums on capital allocated of separate element of equity capital, which is a correction of a previously admitted error of a methodological nature.

As it is known the peculiarity of the national accounting and reporting system of the RM is its directness, which is confirmed by the approval of financial reporting forms, which are periodically amended, and therefore it can be argued that the application of the prescriptive approach does not justify itself with regard to the effectiveness of regulation. This is the second argument in context hypothesis H1.

As regards, the author concludes that in the system of accounting in the RM there is no integral conceptual space for determining the structure and preparation of financial statement, including the SMEs.

The author's point of view is based on the information on prescriptive (legal) approach for preparing the financial statement which is not enough for making economic decisions. Such decisions are increasing the efficiency of using equity capital, attracting new investors, forecasting the growth of the organization's capital as a whole, which is important for owners.

Consequently, that SCEC as form of financial statement of the RM do not meet such a requirement of modern accounting methodology - presentation of reliable information. This is the first argument in context hypothesis $\mathrm{H} 2$. We consider it appropriate to emphasize that at a certain evolutionary stage in the development of the accounting methodology, when the legal approach to the preparation of financial statements dominated, the use of such a format of information in the SCEC was justified. In context with an innovative vector of development of the society, when the basis for the preparation of financial statements according of an economic approach, the purpose of SCEC become to bear a socio-economic nature. As result, the author concludes that SCEC as form of financial statement of the RM do not meet the interests of users of information on the state of equity capital entities, including SMEs. This is the second argument in context hypothesis $\mathrm{H} 2$.

\section{Discussion and Results}

\subsection{Statement of Stockholders' Equity: Conceptual Basis and Evolution}

As it is known, equity capital is one of the most important objects of accounting, as it: embodies the economic resources of the organization, potentially capable of generating revenue, provided they are used effectively; is designed to reflect civil and legal relations between investors in the organization of activity and the organization, while being exclusively an economic category; represents a source ensuring the growth of well-being of its owners. The presentation of information on equity capital and its changes is quite a challenge for any compiler organization, since, as researcher Kovtun (2014) points out, "the concept of disclosure of information on capital is still at the stage of formation and requires proper scientific justification" [21].

There are various approaches to the disclosure of such information, however, the modern methodology of accounting for the recognized criteria that determine the content of this report are: structural components of equity capital, adopted accounting and reporting model, the used by the organization model of capital management, as well as the national characteristics of accounting systems.

We will briefly describe each of the indicated criteria. In accordance with the current accounting and reporting methodology, the organization's equity capital is a part of the total capital and is an internal source of finance for the financial and economic activities generated by: contributions of owners, whose right to their share is confirmed by a sharepart or shares; part of the profits received and undistributed to owners. Hence the two components in the composition of equity capital - the authorized capital (joint-stock or share) and undistributed profits.

Today, we can no longer refute the fact that the effectiveness of the use of equity capital is manifested not only in obtaining income from capital (profit), but also in the ability to maintain its size at the reporting date, which in time changes under the impact of market conditions.

The instrument for realizing this fact is the concept of maintaining the size of capital, the IFRS Concept [4], as well as the jurisdictions of various countries, including the RM, recommend the option of financial capital for use. According to this concept, the financial statements should reflect a part of operating profit directed to maintain the size of the investment made by the owners with a changed purchasing power, as well as the remainder of the profit, which is treated as the profit earned by the organization during the reporting period. This requires reflection in the composition of equity capital of components such as share premium and reserves.

Belonging to one of the two models of accounting and reporting (Anglo-Saxon or Continental) is primarily characterized by the orientation of information on a certain group of users. Under the Anglo-Saxon model, disclosure of information in the financial statements as a whole, and in particular about its equity capital, presents a fairly clear requirement for its completeness, which is explained by the 
fact that the main group of users under this model are the owners of capital (shareholders and investors) both real and potential. The author supports the point of view by Generalova, Soboleva and Sokolova (2016), that AngloSaxon model of financial reporting whose inherent attributes are: the economic approach, economic treatment, professional judgments, etc. [5]

The economic approach is embodied in the IFRS Concept [4], which is the methodological basis of the IFRS system, according to which the completeness requirement is interpreted as a qualitative characteristic of financial reporting that corresponds to the concept of reliability.

With the Continental accounting model, the dominant group of users are creditors and tax authorities, so when disclosing information about equity capital, the emphasis is placed on the accuracy of its (correctness) representation, while the value of completeness is leveled.

It seems logical the analysis of the following factors in determining the disclosure of equity capital - the choice of the concept of capital management of the organization, according to which a number of indicators characterizing the amount of equity at the reporting date is calculated. According to Hendriksen, van Breda (2000), particular importance is acquired by information on changes in equity capital that arise from the application of policies: dividend policy, at which there are changes due to the distribution of profits and settlements with owners; accounting policy, under which changes arise when it is modified and when significant errors are corrected [22].

We consider it appropriate to note that the application of the theory of capital has led to the evolution of the accounting methodology, and as a result, of the financial reporting system. However, from using of any of equity management concepts affects the amount of information provided about equity capital, because this connected with the management decision of a particular organization.

The above indicated is proof that the basic criterion underlying the establishment of the volume of information about equity capital is the information needs of users of financial statements. In the regard, we will consider two generally accepted methods of preparing it, developed by world practice.

The first is to provide information about the income and expenses recognized as a change in capital, in the Statement of profit and loss. Therefore, this format of information on changes in capital is a decoding to the relevant section of the balance sheet information on the reasons for the overall change for capital for the reporting period (except for transactions with the owners). Since this information is not available in the above way of preparing this report, therefore this information disclosed in the explanatory note to the financial statements. The work of Alexander, Britton and Iorisen (2005) features of this format of the report disclosed in detail [23].

However, with innovative direction of economic development, each component of equity capital acquires significance, the emergence of which is due to a certain economic event: one is the result of redistribution of profit, the other is corrective, and the appointment of the third is to maintain the size of the capital. In this context, each component of equity capital acquires significance, the emergence of which is due to a certain economic event: one is the result of redistribution of profit, the other is corrective, and the appointment of the third is to maintain the size of the capital. Therefore, it became an objective necessity to disclose information on the amount of change and the reasons for its occurrence in the context of each component of equity capital. The result of solving this problem was the development of an alternative way of preparing a report on changes in equity capital.

The advantage of the alternative format is not so much the detailed information, but the fact that it allows to reflect the dual essence of capital: 1 - as a combination of components, 2 - as the net assets of the organization (the difference between assets and liabilities), the cost of which is affected by various market factors. As a result of economic events objects of observation of accounting, they (factors) lead to a change in the value of either assets or liabilities, and, consequently, the net assets of the organization. Disclosure of information about each factor allows owners to see the economic impact of each of them on capital gains in the context of its components.

According to Tsurcanu and Golochalova (2015) the prepared SCEC in this way meets the basic concepts of modern accounting methodology, which are the concepts of mixed balance, of reliability, of money management [24]. We emphasize that the designated format of the SCEC in an alternative way is recommended for application by the IFRS system and jurisdictions of a number of countries, however, another version of it is fixed in the RM (see table 6).

\subsection{The Peculiarities of SCEC of System Financial Statement of Republic Moldova}

Now we will try to characterize the adopted SCEC in the system financial statement of Moldova. As is already known, the peculiarity of the national accounting and reporting system of the RM is its directness, which reduces the reliability of the financial statement, but in context of an innovative economy of SCEC in particular. This is the first feature of this report.

As defined in the NAS "Equity capital and liabilities", the Statement on the CEC is intended to disclose the reasons that affected each balance sheet item in the "Equity capital" section, since in the balance sheet these articles contain data only for two items: the balance at the beginning and end of the period. The amounts of factors are reflected in this report as an increase or decrease in equity capital. However, the analysis of the contents of this report allows us to conclude that there are no factors (causes) for changes in it, and the result of these factors is already presented as a specific item of each element of equity capital, for example, the social capital takes the form of unpaid, in certain circumstances, or unregistered, or withdrawn capital. The same approach is maintained for other elements of equity capital (see table 6), 
which, in the author's opinion, leads to a violation of such qualitative characteristics as clarity and reliability. This is the second feature of this report. The third feature of the SCEC being studied is that its vertical format is, in fact, a developed balance format, and despite the simplicity of information presentation, it reduces its qualitative purpose. At first glance, the reflection of capital elements in the reporting does not cause practical problems. However, if you take into account that the changes in capital are largely associated with operations with financial instruments, the compiler organization will have the problem of reliable reporting due to the lack of proven algorithms for preparing information in the accounting and reporting system for this type of operations. This is the next feature of the SCEC due to the problems of accounting methodology in the RM.

Taking into account the above, the author concludes that the SCEC is characterized by simplicity of content and a simplified format of presentation, and as a consequence, initially focused on the needs of the SMEs (the exception is the innovative segment of the SB sector). One of the arguments for this judgment is also the highlighted features of this report.

However, the question arises if the SCEC for most organizations of the SB sector is not necessary for presentation, for medium-sized organizations in this sector, the simplified format reduces the level of completeness of information, for business structures does not meet the interests of users of information on the state of equity capital, then for what organization is it intended? The author supports the opinion by Grigoroi and Muntean (2019) that the new legislative framework RM did not resolve some of the old problems faced by its predecessor, such as provisions relating to the studies of the chief accountant, thus the application of the legal provisions creates confusion regarding its application in practice [3].

The answer to this question is methodological in nature, because it lies in the plane of understanding the modern concept of capital and establishing the optimal ratio of the necessary and permissible amount of information for organizations operating in the era of innovative development of society. In this context author fully supported the views Guohui, Meimei and Le (2018), who consider that research with respect to financial statement of SMEs should be aimed to the construction of financial system, improve the quality of accounting information, accumulation of human capital and social capital [2].

\section{Conclusions}

Based on the results of research this paper puts forward the following conclusions: (1) In general, in the RM the financial statement system should be based on modern accounting methodology, which ensure integrated reporting of information when financial statement has a social-economic nature. Moreover, methodological approach of financial reporting should be unified in the context of dominance of SMEs in the Moldavian economy. (2) The conceptual space in terms of determining the structure of financial reporting and generating reliable information on the results of the small business organizations sector activity in the accounting and financial reporting system of the RM in the context of transition to an innovative development path. This conclusion is argued: by identified controversy in order to prepare the financial statement; by fact that the financial statement is overly prescriptive, but application of the prescriptive approach does not justify itself with regards to the effectiveness of regulation of accounting and reporting, which is periodically amended. (3) The Statement of Stockholders' Equity as form of financial reporting of the $\mathrm{RM}$ does not meet the interests of users of information on the state of equity of capital entities, including SMEs, and requirements of modern accounting methodology. This conclusion is argued: SCEC as form of financial statement does not provide useful information about the reasons for the changers amount of equity capital. Moreover, structure of SCEC must reflect a socio-economic nature of equity capital with regards to innovative direction of economy.

\section{References}

[1] Hu Xuhua, Ocloo Chosniel Elikem, Selorm Akaba, David Worwui-Brown. Effects of Business-To-Business ECommerce Adoption on Competitive Advantage of Small and Medium-Sized Manufacturing Enterprises. Economics and Sociology, 12 (1), 80-99. doi: 10.14254/2071-789X.2019/12$1 / 4$.

[2] Hu Guohui, Zheng Meimei, Zhao Le. Quality of Accounting Information, Executives' Background and Loans of Small and Medium-Sized Enterprises. International Journal of Economics, Finance and Management Science, 2018; 6 (5): 216-223. doi: 10.11648/ijefm.20180605.13.

[3] Grigoroi, Lilia, Muntean, Neli. The Innovative Experience of the Republic of Moldova in Reforming the Accounting System and its Harmonization with IFRS and European Directives. Marketing and Management of Innovations, Issue 1, 2019, retrieved from: http://doi.org/10.21272/mmi.2019.127

[4] Conceptual Framework for Financial Reporting, retrieved from: http://www.ctcp.gov.co/files/documents

[5] Generalova, Natalia, Soboleva, Genrietta and Sokolova, Natalia. Adoptation of IFRS in Russia: 22 Years of Accounting Reforms. Journal of Eastern Europe Research in Business and Economics, Vol. 2016, Article ID 602146, doi: $10.5171 / 2016.602146$.

[6] Cherbuska, Viorica. Financing of small and medium-sized enterprises in the Republic of Moldova: the specificity of inovational enterprises, 2017, retrieved from: http://www.cnaa.md/thesis/50540/

[7] Timotin, Ludmila. Entrepreneurship development in the Republic of Moldova, 2017, retrieved from: http://www.cnaa.md/thesis/51795/

[8] Muska, Svetlana. Motivational management of small and medium-sized enterprises of ATU Gagauzia, 2017, retrieved from: http://www.cnaa.md/thesis/52560/ 
[9] Kot, Sebastian, Goldbach, Ioana Raluca, Ślusarczyk, Beata. Supply Chain Management in SMEs-Polish and Romanian Approach. Journal Economics and Sociology, 2018, 11 (4), 142-156. doi: 10.14254/2071-789X.2018/11-4/9.

[10] Official Statistics, retrieved from: http://www.statistica.md/newsview.php?l=ro.

[11] Aculay, Elena. Improve policy of small and medium-sized enterprises development in the Republic of Moldova, 2015, retrieved from: https://www.ince.md/uploads/files/14.

[12] Communication from the commission to the council, the European Parliament, the European economic and social committee the committee of the regions "Think Small First" a "Small Business Act" for Europe, retrieved from: http://eurlex.europa.eu/legalcontent/EN/TXT/?uri=CELEX:52008DC0394

[13] Government Degree No. 685 of September 13, 2012 in pursuance of the Strategy of the Republic of Moldova for supporting small and medium-sized enterprises on 2012-2020, retrieved from: http://lex.justice.md/file/an.1_685.doc

[14] SME Policy Index: Eastern Partner Countries 2016: Assessing the Implementation of the Small Business Act for Europe, retrieved from: http://dx.doi.org/101787/9789264246249-en

[15] Levitskaia, Alla. Regional Economic Innovative Development (ATU Gagauzia case), 2017, retrieved from: http://www.cnaa.md/thesis/51622/

[16] Law No. 179 of July 21, 2016 of the Republic of Moldova "On Small and Medium-Sized Enterprises" with all subsequent completions and changes, retrieved from: http://www.bnk.md/content/закон-

[17] Law No. 287 of December 15, 2017 of the Republic of
Moldova "On Accounting and Financial Reporting", retrieved from

http://lex.justice.md/viewdoc.php?action=view\&view=doc\&id $=363701$ \&lang $=2$

[18] International Accounting Standard 1 «Presentation of Financial Statements», retrieved from http://ec.europa.eu/docs/arc/ias1_ann.

[19] National Accounting Standards "Presentation of Financial Statements", approved by Order of the Ministry of Finance No. 118 from August 06, 2013, with modification 01.01.2019], retrieved from: http://www.old.mf.gov.md/actnorm//contabil/standartnew/

[20] NAS "Own capital and liabilities" approved by Order of the Ministry of Finance No. 118 from August 06, 2013, retrieved from:

http://www.lex.justice.md/viewdoc.php?action=view\&view=d oc\&id $=349175$

[21] Kovtun, Irina. Conceptual premises of presentation of reporting information of stockholders equity of enterprises//Young Scientist, part IV, 2014, No. 3 (62), pp. 443-448.

[22] Hendriksen, El. S., van Breda, M. F. Accounting Theory.Moscow, 2000: Finance and statistics.

[23] Alexander, David, Britton, Anne, Iorisen, Enn. International Financial Reporting Standards: from theory to practice, Moscow, 2005: Vershina.

[24] Tsurcanu, Viorel, Golochalova, Irina. Conceptual framework for the formation of entity balance sheet. In: Monograph «The Evolution of the Concepts of Accounting is based on the institutional approaches and benchmarking», Zhytomyr, 2015: «Ruta», pp. 89-166. 